\title{
Physiotherapy
}

Physiotherapy xxx (2020) xxx-Xxx

\section{Characteristics of patients with knee and ankle symptoms accessing physiotherapy: self-referral vs general practitioner's referral}

\author{
N.E. Lankhorst ${ }^{a}$, J.A. Barten ${ }^{b}$, R. Meerhof ${ }^{a}$, S.M.A. Bierma-Zeinstra ${ }^{a}$, \\ M. van Middelkoop ${ }^{a, *}$ \\ ${ }^{a}$ Department of General Practice, Erasmus MC, University Medical Centre, Rotterdam, The Netherlands \\ ${ }^{\mathrm{b}}$ Netherlands Institute for Health Services Research, Utrecht, The Netherlands
}

\begin{abstract}
Objectives To determine patient characteristics, frequency of use, type of symptoms and treatment outcomes in patients with knee or ankle symptoms, separately, for patients referred by their general practitioner (GP) and patients who self-referred.

Design Longitudinal study.

Setting Dutch primary care physical therapy practices.

Participants All patients who visited a physiotherapist with knee or ankle symptoms between 2006 and 2012.

Method Data were collected from the NIVEL Primary Care Database. The mode of access (self-referred or GP-referred) was determined for all patients. For analyses, descriptive statistics, unpaired $t$-tests, Chi-square test and logistic regression analyses were applied.

Results The study included 6179 patients with knee or ankle symptoms. The use of self-referral increased from $26 \%$ in 2006 to $56 \%$ in 2012, and stabilised between 2010 and 2012. Self-referred patients were younger, had a higher education level and had a shorter duration of symptoms compared with GP-referred patients. Self-referred patients had fewer treatment sessions than GP-referred patients.

Conclusions Among patients with knee or ankle symptoms, younger patients, and those with a higher education level, a shorter duration of symptoms and recurrent symptoms were more likely to self-refer than other patients. Self-referred patients had fewer treatment sessions. After 2009, the frequency of self-referrals to physical therapists stabilised. Future studies should examine the effectiveness of physical therapy for patients who self-refer with acute knee and ankle symptoms.
\end{abstract}

(C) 2017 Chartered Society of Physiotherapy. Published by Elsevier Ltd. All rights reserved.

Keywords: Direct access; Physiotherapy; Knee; Ankle

\section{Introduction}

Musculoskeletal symptoms (e.g. back, shoulder, knee and ankle) are common in primary care, and account for approximately $12 \%$ of all consultations in general practice in The Netherlands [1,2]. Knee and ankle symptoms are common, with incidence rates of 10.9 to 13.7 per 1000 persons and 3.3 per 1000 persons, respectively $[2,3]$.

\footnotetext{
* Corresponding author at: Department of General Practice, Erasmus MC, University Medical Centre, PO Box 2040, 3000 CA Rotterdam, The Netherlands. Fax: +31 107032127 .

E-mail address: m.vanmiddelkoop@erasmusmc.nl (M. van Middelkoop).
}

Various non-surgical treatment options are available for knee and ankle symptoms, and mainly comprise advice to rest and use analgesic medication for acute traumatic symptoms $[4,5]$. Physiotherapy is also considered for non-traumatic and chronic knee/ankle symptoms, including chronic symptoms due to trauma $[4,6,7]$. In The Netherlands, although physiotherapy is not strongly recommended in the guidelines for general practitioners (GPs), there is evidence that supervised exercise therapy can result in pain reduction and functional improvement compared with usual care in patients with nontraumatic knee symptoms, traumatic knee injury and ankle injury $[4,8-10]$. 
One result of the new healthcare system introduced in The Netherlands in 2006 is that patients no longer need a formal referral by a GP (or other physician) to consult a physiotherapist. This change led to an increase in the number of patients with musculoskeletal complaints consulting physiotherapists through self-referral: in the first year of introduction (2006), $32 \%$ of patients consulted physiotherapists without a referral from a GP, and this increased to $51 \%$ of patients in 2015 $[11,12]$.

Three previous studies in The Netherlands comparing the characteristics of patients who visited a physiotherapist following a GP referral or who self-referred found that selfreferred patients had a higher education level and a shorter duration of symptoms [13-15]. The first study was conducted immediately after the implementation of self-referral and had a shorter duration of follow-up [13], whereas the other two studies evaluated patient characteristics between 2006 and 2009 [14] and between 2006 and 2010 [15]. However, the studies included patients with back pain alone [14] or patients with diverse types of musculoskeletal disease (e.g. back, neck, shoulder) [15], and patients with knee and ankle symptoms may differ from these patients. Patients with knee and ankle symptoms are more likely to be distributed between different age groups (including young and older patients), and will probably include a percentage of traumatic symptoms that could impact the choice of care $[4,5]$.

To date, no studies have examined the association between patient characteristics and the mode of access to physiotherapy among patients with knee or ankle symptoms. As knee and ankle complaints are among the most common types of symptoms in physiotherapy practice, physiotherapy is considered as treatment for both in primary care, and both represent traumatic and non-traumatic patients, the primary aims of this study were: (i) to establish the distribution in mode of access of patients with knee or ankle symptoms between 2006 and 2012; and (ii) to investigate the differences in patient and treatment characteristics between GP-referred patients and self-referred patients, and to identify the characteristics associated with self-referral.

\section{Methods}

Data were collected from the NIVEL Primary Care Database (NPCD), formerly known as the National Information Service for Allied Health Care. NPCD consists of longitudinal data, collected by extraction of routinely recorded data in the healthcare provider's electronic health record system. The data collected by NPCD are for a representative sample of the Dutch population, and include data on health problems and treatment. GPs, physiotherapists, exercise therapists, dieticians, primary care psychologists and GP out-of-hours services contribute to NPCD. In the current study, only data and registrations of patients who visited a physiotherapist were used. The physiotherapists were selected from those who work extramurally (in the commu- nity) in The Netherlands, and are nationally representative by regional distribution. More detailed information about NPCD has been published previously [13-15].

\section{Study population}

The study population consisted of all patients who visited a physiotherapist with knee or ankle symptoms between 2006 and 2012. Knee and ankle symptoms were identified using the International Classification of Primary Care (ICPC) [16]. Each treatment episode represented in NPCD was linked to one or more ICPC codes. In the case of GP referral, the written record made by the referring GP was recoded; in the case of self-referral, the main health problem was recoded into an ICPC code. A digital self-learning module developed over the last 10 years of registration recognises text words and codes $90 \%$ of cases automatically into ICPC codes. The additional $10 \%$ are entered manually into the database. A research assistant monitored and verified this digitalised recoding process. The following ICPC codes were used to select patients with knee symptoms: knee symptoms and complaints (L15), knee sprain/distortion (L78), osteoarthritis of the knee (L90), Osgood-Schlatter/osteochondritis dissecans (L94), acute meniscal or ligamental injury (L96), chronic internal knee trauma (L97), patellofemoral syndrome (L99.07), corpus liberum (L99.10) and pseudarthrosis (L99.11). To select patients with ankle symptoms, the following codes were used: ankle symptoms and symptoms (L16) and ankle sprain/distortion (L77). The types of symptoms were divided into traumatic and non-traumatic symptoms. Knee sprain/distortion (L78) and meniscal or ligamental injury (L96) were used to describe traumatic knee symptoms. Ankle sprain/distortion (L77) was used to define traumatic ankle symptoms.

In NCPD, each episode of knee or ankle symptoms was registered separately. An episode was defined as the occurrence of knee or ankle symptoms from the start of the first consultation to the end of treatment between 2006 and 2012; to avoid double counting of individual patients, only the first episode of care was included for patients with multiple episodes. Patients were excluded if the mode of access was not reported, if they had both knee and ankle symptoms in the same episode, or if they were referred by a physician other than a GP.

Ethical approval was not required because NPCD does not fall within the scope of the Medical Research Involving Human Subjects Act. Data were collected anonymously and patients were informed about the research by posters and leaflets in practice waiting rooms. The study adhered to the tenets of the Declaration of Helsinki.

\section{Measurements}

Between 2006 and 2012, the following data were collected for each episode. 


\section{Patient characteristics}

Age (years), sex, urbanisation (urban/rural), patient identification number, and educational level in patients aged $>16$ years. Education level was categorised as lower education (primary school, lower vocational education or lower secondary education), middle education (intermediate vocational education or intermediate/higher secondary education) and higher education (higher vocational education and university).

\section{Referral}

Diagnosis (based on ICPC code) and mode of access (selfreferral or GP referral).

\section{Health problem}

Recurrence of knee or ankle symptoms (visiting a physiotherapist with the same symptoms more than 3 months after the termination of care for the first episode) (yes/no) and duration of symptoms ( $\leq 7$ days, 1 week to 1 month, 1 month to 12 months, $\geq 12$ months).

\section{Treatment}

Number of visits to the physiotherapist for current episode, and duration of treatment episode (total number of days that the patient visited a physiotherapist).

\section{Evaluation}

Self-reported reason for termination of care (goals achieved, no insurance, terminated by patient, terminated by physiotherapist or terminated by referrer) and self-reported results on the basis of the treatment goal set at the start of treatment (achieved, partially achieved or not achieved).

\section{Data analyses}

Data on knee and ankle symptoms were analysed separately. Analyses were performed using STATA Version 13.0 (StataCorp, College Station, TX, USA).

Patient characteristics, treatment outcomes and evaluation of treatment were analysed using descriptive statistics. Differences between GP referral and self-referral were analysed using unpaired $t$-tests in the case of normally distributed data; Chi-squared tests were used in the case of non-normally distributed and discrete data.

A multivariate logistic regression model with backward stepwise selection $[P$ (in) $0.05, P$ (out) 0.10$]$ was used to study the association between mode of access to physiotherapy and patient characteristics in patients with knee or ankle symptoms. The following characteristics were included in the analysis: sex, age, diagnosis, education level, urbanisation, duration of symptoms and recurrent symptoms. Associations were presented as odd ratios (ORs) with 95\% confidence intervals $(95 \% \mathrm{CI})$. To check whether missing data biased the results, an additional multivariate logistic regression analysis was performed; this included dummy variables (with variable

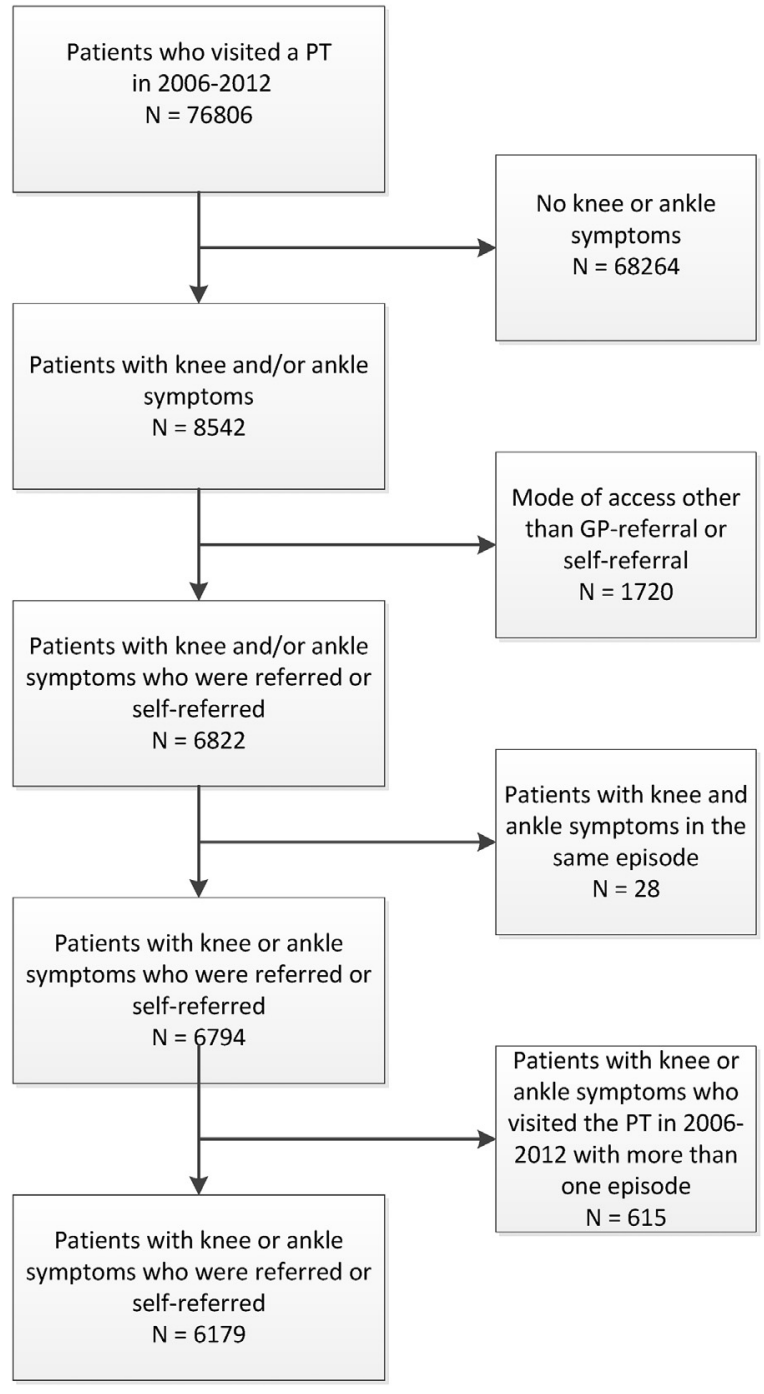

Fig. 1. Patient flowchart. PT, physiotherapist.

'missing') and compared the outcomes of both models (with and without the dummy variables).

\section{Results}

\section{Study population}

From the initial 76806 patients who visited a physiotherapist between 2006 and 2012, 6179 patients with knee or ankle symptoms were selected for inclusion in this study (Fig. 1). Of these, the mean age was 41 (range 4 to 101) years, and $2869(46 \%)$ were men. In total, 4688 (76\%) patients were diagnosed with a knee complaint and $1491(24 \%)$ patients were diagnosed with an ankle complaint (Table 1). Patients with missing data were had an older mean age and more often had injuries of traumatic origin compared with patients with complete data.

The majority of patients with knee or ankle symptoms (62\%) visited a physiotherapist following referral by a GP. 
Table 1

Characteristics of patients visiting a physiotherapist due to knee or ankle symptoms, by mode of access.

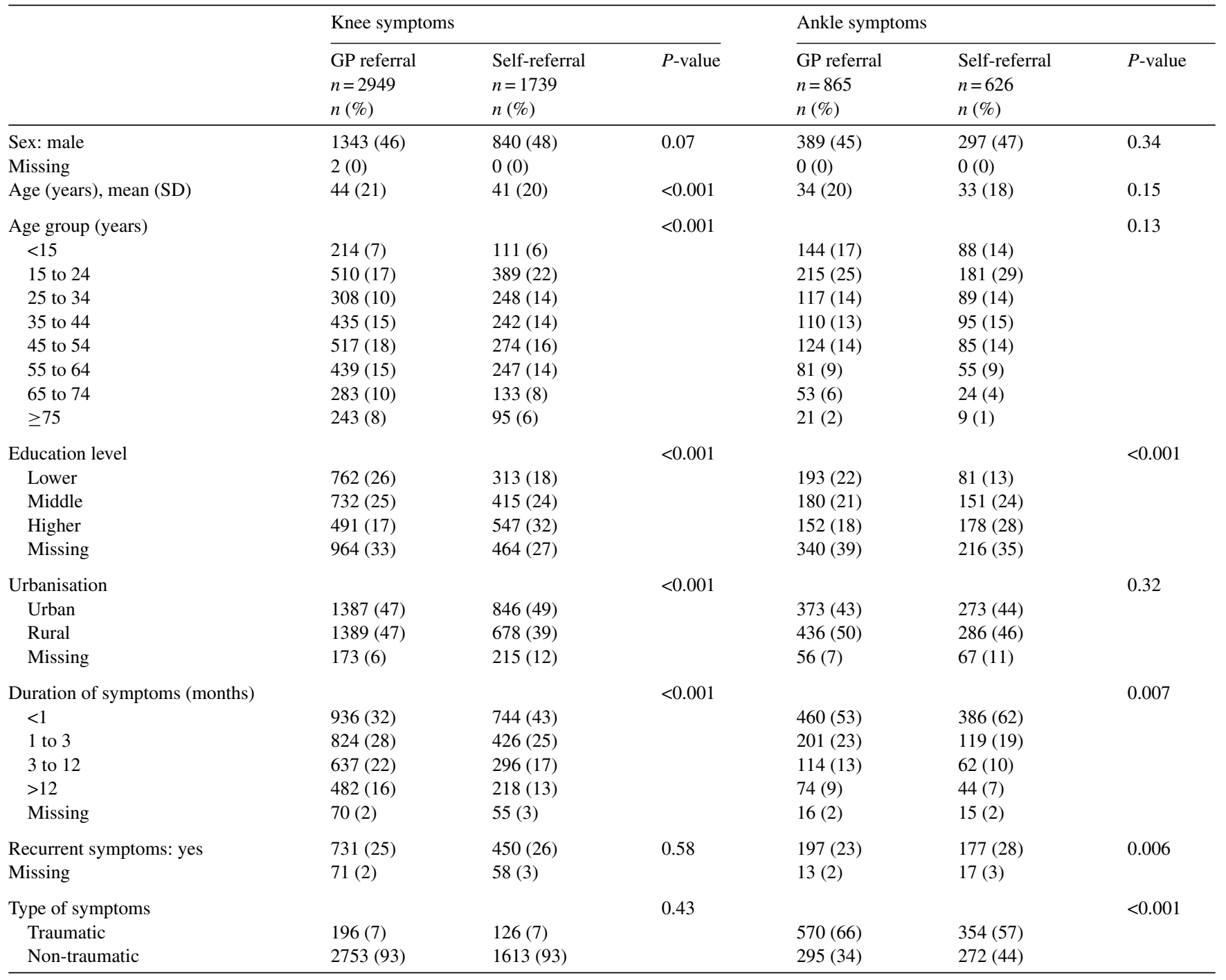

GP, general practitioner.

Table 2

Specification of knee and ankle symptoms, separately, for each mode of access.

\begin{tabular}{|c|c|c|c|c|}
\hline Diagnosis (ICPC code) & $\begin{array}{l}\text { Total population } \\
n(\%)\end{array}$ & $\begin{array}{l}\text { GP referral } \\
n(\%)\end{array}$ & $\begin{array}{l}\text { Self-referral } \\
n(\%)\end{array}$ & $\begin{array}{l}P \text {-value } \\
\text { Overall }\end{array}$ \\
\hline Knee symptoms & 4688 & 2949 & 1739 & $<0.001$ \\
\hline Knee symptoms/complaints (L15) & $3509(75)$ & $2071(70)$ & $1438(83)$ & \\
\hline Sprained knee (L78) & $240(5)$ & $145(5)$ & $95(6)$ & \\
\hline Osteoarthritis of the knee (L90) & $382(8)$ & $295(10)$ & $87(5)$ & \\
\hline Osgood-Schlatter (L94.02) & $28(1)$ & $23(1)$ & $5(0)$ & \\
\hline Acute meniscal injury (L96) & $82(2)$ & $51(2)$ & $31(2)$ & \\
\hline Chronic internal trauma knee (L97) & $14(0)$ & $12(0)$ & $2(0)$ & \\
\hline Patellofemoral syndrome (L99.07) & $433(9)$ & $352(12)$ & $81(5)$ & \\
\hline Ankle symptoms & 1491 & 865 & 626 & $<0.001$ \\
\hline Ankle symptoms/complaints (L16) & $567(38)$ & $295(34)$ & $272(43)$ & \\
\hline Sprained ankle (L77) & $924(62)$ & $570(66)$ & $354(57)$ & \\
\hline
\end{tabular}

ICPC, International Classification of Primary Care; GP, general practitioner.

$P$-values show a significant difference in distribution of diagnoses between the GP-referral and self-referral groups. 
Of all patients with knee symptoms, $75 \%$ were diagnosed with 'knee symptoms/complaints (L15)'. Other common knee diagnoses were 'patellofemoral syndrome' (9\%) and 'osteoarthritis of the knee' $(8 \%)$. The most common ankle symptom (62\%) was 'sprained ankle (L77)'. The majority of patients diagnosed with 'knee symptoms/complaints' were self-referrals. Of the patients with ankle complaints who self-referred, the most common diagnosis was 'sprained ankle' $(57 \%)$. However, of all patients with ankle complaints, the most common mode of access was GP referral (Table 2).

\section{Time trends in mode of access}

The proportion of self-referred patients with knee or ankle symptoms increased from 26\% in 2006 to 56\% in 2012 (Fig. 2). This increase was mainly observed between 2006 and 2009.

\section{Characteristics of patients with knee symptoms}

Compared with GP-referred patients, self-referred patients with knee symptoms were younger (41 vs 44 years, respectively), had a higher education level, lived in more urbanised areas, and had a shorter duration of symptoms (Table 1).

Furthermore, patients with knee symptoms who selfreferred had fewer physiotherapy sessions and treatment days compared with patients who were referred by a GP: 6.3 vs 9.1 sessions and 49.7 vs 60.2 days, respectively (Table 3 ).

Multivariate regression analyses showed that patients with knee symptoms were more likely to self-refer if they had a higher education level (OR 2.65; 95\% CI 2.19 to 3.20), and were less likely to self-refer if they were aged 25 to 44 years (OR 0.72 ; $95 \%$ CI 0.58 to 0.89 ) or 45 to 64 years (OR 0.67 ; $95 \%$ CI 0.54 to 0.82 ) (compared with the reference category aged $<25$ years), and had a longer duration ( $>1$ month) of symptoms (OR 0.57 to 0.65 ) (Table 4).

\section{Characteristics of patients with ankle symptoms}

Patients with ankle symptoms who self-referred had a higher level of education, lived in more urbanised areas, reported a shorter duration of symptoms, and were more likely to report recurrent symptoms compared with GPreferred patients. Patients referred by a GP had more traumatic symptoms compared with patients who selfreferred (Table 1).

Moreover, patients with ankle symptoms who self-referred had fewer treatment sessions than patients who were referred by a GP (5.6 vs 6.7 sessions) (Table 3 ).

Similar to patients with knee symptoms, multivariate analyses showed that patients with ankle symptoms were more likely to self-refer if they had a higher education level (OR $2.74 ; 95 \%$ CI 1.94 to 3.86), and were less likely to self-refer if they were aged 25 to 44 years (OR 0.72 ; $95 \%$ CI 0.52 to
0.99 ) or $>65$ years (OR 0.53; 95\% CI 0.29 to 0.98 ) (compared with the reference category aged $<25$ years), had traumatic ankle symptoms (sprained ankle) (OR 0.54; 95\% CI 0.40 to 0.72 ) and had a longer duration ( $>1$ months) of symptoms (OR 0.54 to 0.70 ) (Table 4).

\section{Discussion}

This study examined differences in characteristics between patients with knee or ankle symptoms who visited a physiotherapist following referral by a GP compared with patients who self-referred. In 2006, $26 \%$ of all patients who visited a physiotherapist chose to self-refer, and this increased to $56 \%$ of all patients in 2012; this growth stabilised between 2010 and 2012. Furthermore, younger patients with a higher education level and a shorter duration of symptoms were more likely to self-refer.

It is reported that older patients and those with a longer duration of symptoms are at higher risk of comorbidity and more complex and chronic symptoms, resulting in more visits to a GP [17-19]. This is supported by the current finding that patients were less likely to self-refer if they suffered from a diagnosis with higher prevalence among older patients and of a more chronic nature (e.g. osteoarthritis).

Similar to other studies, the patients in this study with a shorter duration ( $<1$ month) of symptoms were more likely to refer themselves to a physiotherapist $[13,14]$. It has recently been shown that $87 \%$ of self-referred patients with musculoskeletal symptoms who visited a physiotherapist were in fact treated by a physiotherapist after the initial visit [15]. It therefore seems that a large percentage of self-referred patients who seek help for their musculoskeletal symptoms (including knee and ankle symptoms) are actually treated by their physiotherapist. GPs are generally regarded as gatekeepers of care and may be less likely to refer patients to a physiotherapist when there is doubt regarding the effectiveness of treatment. From this perspective, it is remarkable that evidence on the (cost-)effectiveness of physiotherapy for acute knee and ankle symptoms (duration of symptoms $<1$ month) is lacking. Also, the present study found that the patient characteristics associated with self-referral are comparable with the prognostic factors for better recovery rates in both knee and ankle symptoms reported by others (e.g. younger age, shorter duration of symptoms, higher level of education) $[20,21]$. This may indicate that these patients are more likely to have a positive outcome, with or without treatment from a physiotherapist. Therefore, information on prognostic factors for recovery and a positive treatment outcome would be valuable for physiotherapists for future decision-making at first visit (e.g. to treat, refer, or wait and see).

Patients with knee or ankle symptoms who self-referred to a physiotherapist had fewer treatment sessions and days of treatment compared with patients who were referred by a GP. These results are consistent with other studies that compared 


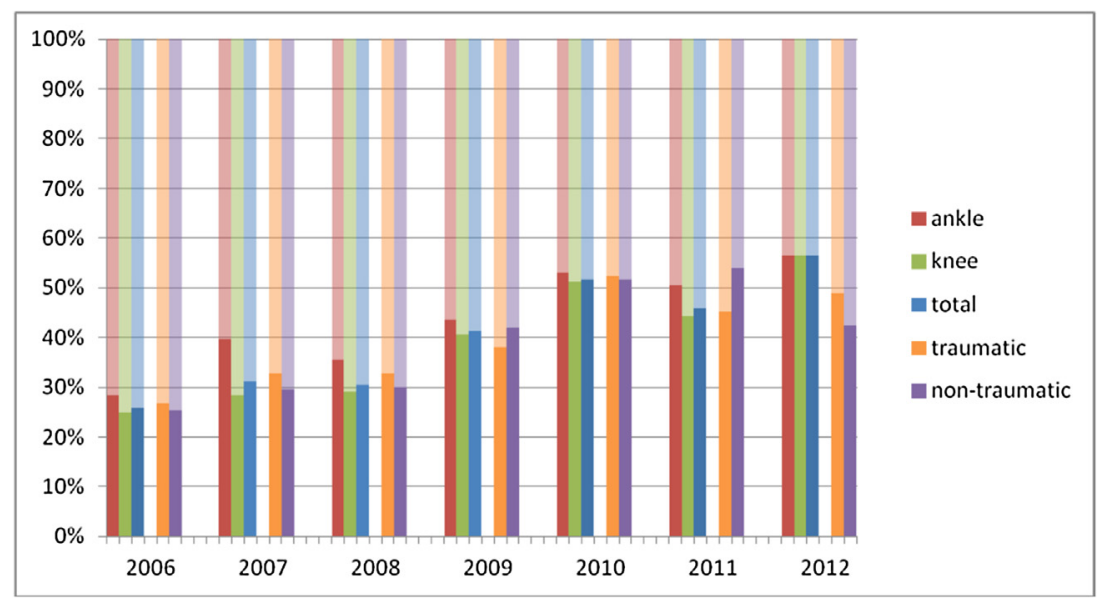

Fig. 2. Distribution of the mode of access in patients with knee or ankle symptoms between 2006 and 2012. Darker bars represent self-referred patients, and lighter bars represent patients referred by a general practitioner.

Table 3

Treatment characteristics of patients visiting a physiotherapist due to knee or ankle symptoms, separately, by mode of access.

\begin{tabular}{|c|c|c|c|c|c|c|}
\hline & \multicolumn{3}{|c|}{ Knee symptoms } & \multicolumn{3}{|c|}{ Ankle symptoms } \\
\hline & $\begin{array}{l}\text { GP referral } \\
n=2949\end{array}$ & $\begin{array}{l}\text { Self-referral } \\
n=1739\end{array}$ & $P$-value & $\begin{array}{l}\text { GP referral } \\
n=865\end{array}$ & $\begin{array}{l}\text { Self-referral } \\
n=626\end{array}$ & $P$-value \\
\hline \multicolumn{7}{|l|}{ Treatment sessions ${ }^{\mathrm{a}}$} \\
\hline Number of sessions, mean (SD)* & $9.1(11.2)$ & $6.3(7.14)$ & $<0.001$ & $6.7(7.4)$ & $5.6(6.1)$ & 0.006 \\
\hline Duration of treatment episode in days, mean (SD) & $60.2(98.6)$ & $49.7(74.4)$ & $<0.001$ & $43.9(60.7)$ & $41.7(58.4)$ & 0.52 \\
\hline Goals accomplished? ${ }^{\mathrm{b}}$ & & & 0.17 & & & 0.25 \\
\hline Goals accomplished & $979(33.2)$ & $541(31.1)$ & & $400(46.2)$ & $218(34.8)$ & \\
\hline Goals partially accomplished & $358(12.1)$ & $196(11.3)$ & & $64(7.4)$ & $49(7.8)$ & \\
\hline Goals not accomplished & $121(4.1)$ & $48(2.8)$ & & $17(2.0)$ & $11(1.8)$ & \\
\hline Reason for termination of care ${ }^{c}$ & & & 0.01 & & & 0.77 \\
\hline Goals accomplished & $1148(39.0)$ & $634(36.5)$ & & $439(50.8)$ & $260(41.5)$ & \\
\hline No compensation insurance & $29(1.0)$ & $7(0.4)$ & & $5(0.6)$ & $2(0.3)$ & \\
\hline Terminated by patient & $94(3.2)$ & $28(1.6)$ & & $12(1.4)$ & $9(1.4)$ & \\
\hline Terminated by therapist & $106(3.6)$ & $48(2.8)$ & & $14(1.6)$ & $10(1.6)$ & \\
\hline Terminated by referrer & $8(0.3)$ & $2(0.1)$ & & $5(0.6)$ & $1(0.2)$ & \\
\hline Missing & & & & & & \\
\hline
\end{tabular}

GP, general practitioner; $\mathrm{SD}$, standard deviation.

Missing data: ${ }^{\mathrm{a}} n=772 ;{ }^{\mathrm{b}} n=3177 ;{ }^{\mathrm{c}} n=3318$.

differences in treatment characteristics between GP-referred and self-referred patients [13,22-25].

Although patients who visited a physiotherapist without referral by a GP had fewer treatment sessions compared with patients who were referred by a GP, it remains unclear whether the difference in the number of treatment sessions is due to the mode of access or other patient characteristics. Therefore, based on the data from this study, no conclusions can be drawn about the cost-effectiveness of self-referral.

\section{Strengths and limitations}

The differences in patient characteristics between patients who self-referred and patients referred by a GP are in agreement with two earlier studies conducted in The Netherlands $[13,14]$. These studies also found that education level and duration of the complaint were associated with self-referral. However, the present study also analysed the effects of the availability of self-referral over a longer period of time in specific musculoskeletal symptoms (i.e. knee and ankle). Therefore, the present study provides information on differences between patients with traumatic and non-traumatic knee and ankle symptoms, as well as more insight into the effects of the implementation of self-referral 6 years after its implementation in this specific patient group.

All diagnoses in the present study were based on ICPC codes [16]. These codes were allocated by a computer program developed by NIVEL. Although all diagnoses were provided by the same computer program, some methodological differences may exist in the allocation of the diagnosis between patients with and without a GP referral. In patients using self-referral, all details on the diagnosis came from the physiotherapist's record, whereas for GP-referred patients, the exact wording of the GP's referral was recoded. Due to this methodological difference, the prevalence rates presented in this study should be interpreted with caution. 
Table 4

Multivariate logistic regression for factors associated with the use of self-referral in patients with knee or ankle symptoms.

\begin{tabular}{|c|c|c|c|c|}
\hline & \multicolumn{2}{|l|}{ Knee symptoms } & \multicolumn{2}{|l|}{ Ankle symptoms } \\
\hline & Odds ratio $(95 \% \mathrm{CI})$ & $P$-value & Odds ratio $(95 \% \mathrm{CI})$ & $P$-value \\
\hline \multicolumn{5}{|l|}{ Age group (years) } \\
\hline$<25$ & 1.00 (reference) & & 1.00 (reference) & \\
\hline 25 to 44 & $0.72(0.58$ to 0.89$)$ & 0.002 & $0.72(0.52$ to 0.99$)$ & 0.05 \\
\hline 45 to 64 & $0.67(0.54$ to 0.82$)$ & $<0.001$ & $0.72(0.51$ to 1.02$)$ & 0.07 \\
\hline$>65$ & $0.80(0.61$ to 1.05$)$ & 0.11 & $0.53(0.29$ to 0.98$)$ & 0.04 \\
\hline \multicolumn{5}{|l|}{ Disorder } \\
\hline Knee symptoms/complaints (L15) & 1.00 (reference) & 0.004 & & \\
\hline Sprained knee (L78) & $0.61(0.43$ to 0.86$)$ & 0.001 & & \\
\hline Osteoarthritis of the knee (L90) & $0.58(0.42$ to 0.80$)$ & 0.51 & & \\
\hline Osgood-Schlatter (L94.02) & $0.46(0.05$ to 4.52$)$ & 0.18 & & \\
\hline Acute meniscal injury (L96) & $0.71(0.43$ to 1.17$)$ & 0.06 & & \\
\hline Chronic internal trauma knee (L97) & $0.23(0.05$ to 1.07$)$ & $<0.001$ & & \\
\hline Patellofemoral syndrome (L99.07) & $0.28(0.20$ to 0.39$)$ & & & \\
\hline Ankle symptoms/complaints (L16) & & & 1.00 (reference) & \\
\hline Sprained ankle (L77) & & & $0.54(0.40$ to 0.72$)$ & $<0.001$ \\
\hline \multicolumn{5}{|l|}{ Education level } \\
\hline Lower & 1.00 (reference) & & 1.00 (reference) & \\
\hline Middle & $1.39(1.15$ to 1.67$)$ & 0.001 & $1.65(1.16$ to 2.34$)$ & 0.005 \\
\hline Higher & $2.65(2.19$ to 3.20$)$ & $<0.001$ & $2.74(1.94$ to 3.86$)$ & $<0.001$ \\
\hline \multicolumn{5}{|l|}{ Duration of symptoms (months) } \\
\hline$<1$ & 1.00 (reference) & & 1.00 (reference) & \\
\hline 1 to 3 & $0.65(0.54$ to 0.78$)$ & $<0.001$ & $0.70(0.50$ to 0.98$)$ & 0.04 \\
\hline 3 to 12 & $0.58(0.47$ to 0.72$)$ & $<0.001$ & $0.49(0.31$ to 0.78$)$ & 0.003 \\
\hline$>12$ & $0.57(0.45$ to 0.73$)$ & $<0.001$ & $0.54(0.40$ to 0.72$)$ & $<0.001$ \\
\hline Recurrent symptoms: yes & $1.24(1.04$ to 1.47$)$ & 0.01 & - & \\
\hline
\end{tabular}

CI, confidence interval.

To check whether missing data biased the results, a regression analysis was performed, including dummy variables for missing data for each variable. The dummy variables for missing data of urbanisation and education were significantly associated with self-referral in the final model for patients with ankle complaints; missing urbanisation data was significantly associated with self-referral in the final model for patients with knee complaints. However, these findings did not influence the ORs of the other variables included in the models. The high percentage of missing data for education level can be explained by the fact that this variable was only created in patients aged $>16$ years.

An important limitation of this study is that the severity of complaints was not measured. As 'severity of symptoms' has been suggested as a possible explanatory factor for the lower number of treatment sessions in patients that self-referred, the interpretation of 'treatment duration' and 'number of visits' is questionable [13,22,25]. In addition, the variables 'goals accomplished' and 'reasons for termination of care' had a high percentage of missing data (missing $>50 \%$ ). Due to the high percentage of missing data, these variables were not included in the multivariate regression analyses.

Future research should aim to identify differences in the reasons for termination of care, and differences in the severity of symptoms (e.g. pain and function scores) between patients with knee or ankle disorders who self-referred compared with patients who were referred by a GP. The severity of symptoms (e.g. based on the International Classification of Functioning, Disability and Health) [26] and functional capacity $[27,28]$ could at least be assessed at the beginning and end of a treatment session, but diagnosis and grading of an injury will also provide essential information. The predefined treatment goal could be based on the magnitude of the difference in symptoms before and after the treatment session. By standardising these treatment goals, differences in treatment outcomes between patients who self-referred and those who were referred by a GP can be determined.

In countries where self-referral is already implemented [29], researchers should be aware of the differences in patient characteristics between patients who visit a physiotherapist with or without a GP referral, as shown in the present study. These differences could lead to the selection of a specific patient population when recruiting in a single setting. Finally, the results of the present study are important for physiotherapists and GPs as they need to be fully aware of their responsibilities following the implementation of self-referral.

\section{Conclusion}

Since 2006, patients have increasingly used self-referral to visit a physiotherapist; self-referral rates stabilised after 2009. The use of self-referral among patients with knee/ankle symptoms is associated with younger age, higher education level and a shorter duration of symptoms. Furthermore, treatment characteristics (e.g. number of treatment ses- 
sions, duration of treatment) differed between GP-referred and self-referred patients. Future studies should examine the effectiveness of physiotherapy following self-referral in patients with acute knee and ankle symptoms.

Ethical approval: Ethical approval was not sought because NPCD does not fall within the scope of the Medical Research Involving Human Subjects Act.

Funding: This study was partly financially endorsed by the Dutch Arthritis Foundation as center of excellence "Optimizing care for osteoarthritis and other chronic musculoskeletal disorder in primary care".

Conflict of interest: None declared.

\section{Appendix A. Supplementary data}

Supplementary data associated with this article can be found, in the online version, at http://dx.doi.org/10.1016/j. physio.2017.03.008.

\section{References}

[1] Davis IS, Powers CM. Patellofemoral pain syndrome: proximal, distal, and local factors, an international retreat, April 30-May 2, 2009, Fells Point, Baltimore, MD. J Orthop Sports Phys Ther 2010;40:A1-16.

[2] Spronk I, Ursum J, Davids R, Stirbu I, Nielen MMJ, Korevaar JC, et al. Huisarts - Top-20 diagnoses bij contacten met de huisartsenpraktijk naar geslacht. Uit: NIVEL Zorgregistraties eerste lijn; 2013. Available at: www.nivel.nl/node/3444. [Accessed 16 May 2017].

[3] Van der Linden MW, Westert GP, De Bakken DH, Schellevis FG. Tweede Nationale Studie naar ziekten en verrichtingen in de huisartspraktijk. Klachten en aandoeningen in de bevolking en in de huisartspraktijk. Utrecht/Bilthoven: NIVEL/RIVM; 2004.

[4] Belo J, Buis P, van Rijn RM, Sentrop-Snijders E, Steenhuisen S, Wilkens C, et al. NHG-Standaard Enkelbandletsel (tweede herziening). Huisarts Wet 2012;55(8).

[5] Belo JN, Berg HF, Klein Ikkink AJ, Wildervanck-Dekker CMJ, Smorenburg HAAJ, Draijer LW. NHG-Standaard Traumatische knieproblemen (Eerste herziening). Huisarts Wet 2010;54:147-58.

[6] Belo JN, Bierma-Zeinstra SMA, Raaijmakers AJ, Van der Wissel F, Opstelten W. NHG-Standaard Niet-traumatische knieproblemen bij volwassenen (Eerste herziening). Huisarts Wet 2008;51:229-40.

[7] Breedveldt Boer HP, Klaassen WRC, Spinnewijn WEM, Heinen N, Burggraaff HB, Derks CJT, et al. NHG-Standaard Niet-traumatische knieproblemen bij kinderen en adolescenten (Eerste herziening). Huisarts Wet 2009:52:332-41.

[8] McAlindon TE, Bannuru RR, Sullivan MC, Arden NK, Berenbaum F, Bierma-Zeinstra SM, et al. OARSI guidelines for the non-surgical management of knee osteoarthritis. Osteoarthr Cartil 2014;22:363-88.

[9] van Linschoten R, van Middelkoop M, Berger MY, Heintjes EM, Verhaar JA, Willemsen SP, et al. Supervised exercise therapy versus usual care for patellofemoral pain syndrome: an open label randomised controlled trial. BMJ 2009;339:b4074.
[10] van Rijn RM, van Ochten J, Luijsterburg PA, et al. Effectiveness of additional supervised exercises compared with conventional treatment alone in patients with acute lateral ankle sprains: systematic review. BMJ 2010;341:c5688.

[11] Kooijman MK, Barten JA, Verberne LDM, Leemrijse CJ, Veenhof C, Swinkels ICS. Fysiotherapie - wijze van toegang. Utrecht: NIVEL; 2013. Available at: www.nivel.n1/node/3238. [Accessed 16 May 2017].

[12] Barten JA, Koppes LLJ. Zorg door de fysiotherapeut - wijze van toegang. Utrecht: Nivel; 2017. Available at: www.nivel.nl/node/4674. [Accessed 16 May 2017].

[13] Leemrijse CJ, Swinkels IC, Veenhof C. Direct access to physical therapy in the Netherlands: results from the first year in community-based physical therapy. Phys Ther 2008;88:936-46.

[14] Scheele J, Vijfvinkel F, Rigter M, Swinkels IC, Bierman-Zeinstra SM, Koes BW, et al. Direct access to physical therapy for patients with low back pain in the Netherlands: prevalence and predictors. Phys Ther 2014;94:363-70.

[15] Swinkels IC, Kooijman MK, Spreeuwenberg PM, Bossen D, Leemrijse CJ, Dijk CE, et al. An overview of 5 years of patient self-referral for physical therapy in the Netherlands. Phys Ther 2014;94(December (12)):1785-95.

[16] WOMAC International. International classification of primary care. 2nd ed. Oxford: Oxford University Press; 2003.

[17] Cimmino MA, Ferrone C, Cutolo M. Epidemiology of chronic musculoskeletal pain. Best Pract Res Clin Rheumatol 2011;25:173-83.

[18] Hagen KB, Bjorndal A, Uhlig T, Kvien TK. A population study of factors associated with general practitioner consultation for non-inflammatory musculoskeletal pain. Ann Rheum Dis 2000;59: 788-93

[19] Jordan KP, Kadam UT, Hayward R, Porcheret M, Young C, Croft P. Annual consultation prevalence of regional musculoskeletal problems in primary care: an observational study. BMC Musculoskelet Disord 2010;11:144.

[20] Kastelein M, Luijsterburg PA, Belo JN, Verhaar JA, Koes BW, BiermaZeinstra SM. Six-year course and prognosis of nontraumatic knee symptoms in adults in general practice: a prospective cohort study. Arthritis Care Res (Hoboken) 2011;63:1287-94.

[21] O'Connor SR, Bleakley CM, Tully MA, McDonough SM. Predicting functional recovery after acute ankle sprain. PLoS One 2013;8: e72124.

[22] Mitchell JM, de Lissevoy G. A comparison of resource use and cost in direct access versus physician referral episodes of physical therapy. Phys Ther 1997;77:10-8.

[23] Ojha HA, Snyder RS, Davenport TE. Direct access compared with referred physical therapy episodes of care: a systematic review. Phys Ther 2014;94:14-30.

[24] Holdsworth LK, Webster VS. Direct access to physiotherapy in primary care: now? - and into the future? Physiotherapy 2004;90:64-72.

[25] Pendergast J, Kliethermes SA, Freburger JK, Duffy PA. A comparison of health care use for physician-referred and self-referred episodes of outpatient physical therapy. Health Serv Res 2012;47:633-54.

[26] World Health Organization. International classification of functioning, disability, and health. Geneva: WHO; 2001.

[27] de Bie RA, de Vet HC, van den Wildenberg FA, Lenssen T, Knipschild PG. The prognosis of ankle sprains. Int J Sports Med 1997;18:285-9.

[28] Tegner Y, Lysholm J. Rating systems in the evaluation of knee ligament injuries. Clin Orthop Relat Res 1985;198:43-9.

[29] Bury TJ, Stokes EK. A global view of direct access and patient selfreferral to physical therapy: implications for the profession. Phys Ther 2013;93:449-59.

Available online at www.sciencedirect.com

\section{ScienceDirect}

